\title{
Polymer functionalization by luminescent supramolecular gels
}

\author{
Hirotaka Ihara ${ }^{1,2}$, Makoto Takafuji ${ }^{1}$ and Yutaka Kuwahara ${ }^{1}$ \\ In this review, we describe luminescent supramolecular gels that are formed by the self-assembly of low-molecular-weight \\ compounds, focusing specifically on glutamide-based derivatives. We have developed various glutamides as supramolecular \\ gel-forming compounds, and their unique features are characterized by the fact that most of the derivatives can form nanofibrils \\ based on highly ordered aggregation in aqueous and organic solutions. The aggregated states are often accompanied by \\ supramolecular functions. For example, when the glutamide has an optically functional group, such as a fluorophore, the \\ produced aggregates show unique optical functions such as enhanced chirality (circular dichroism), fluorescence with a large \\ Stokes shift and circularly polarized luminescence. Interestingly, these functions can be achieved in polymer-mixed systems. \\ Because the glutamides form nanofibrillar networks even in polymers, the obtained polymer composites remain transparent \\ because of low light scattering. Supramolecular functions are introduced in the presence of glutamide aggregates. \\ This paper also describes polymer functionalization with glutamide-based supramolecular gels and their applications in light \\ management technologies.
}

Polymer Journal (2016) 48, 843-853; doi:10.1038/pj.2016.53; published online 1 June 2016

\section{INTRODUCTION}

Transparent materials are widely applied in material and energy conversion processes that use light as an energy source. There is currently a strong demand for transparent materials to replace inorganic glasses, particularly those that are lighter and more flexible, and possess special functionality. The candidate materials best matching these criteria are organic polymers. However, inorganic glasses exhibit high durability because of their high heat, light and chemical resistance. Inorganic glasses have some disadvantages, but presently they are still the most widely used transparent material.

The potential of polymer materials is increasing beyond their conventional advantages of being light weight and flexible because they allow for the possibility of diverse functional designs. An example of applying this functionality is through the blending of polymer materials with fillers such as inorganic oxide particles. This method has been widely adopted for the functional reinforcement and conversion of generic polymers. The use of nanosized fillers limits light scattering, so such fillers are becoming favored for applications requiring transparency. For example, blending polymers with inorganic nanoparticles such as zirconia or titania can provide a high refractive index that cannot be achieved solely with polymer materials. $^{1-6}$ Blended polymers (nanocomposites) incorporating clays, silica, carbon nanotubes and magnetic particles have also received much research attention. ${ }^{7-12}$ They have been used to suppress gas permeability, improve strength and both the heat and flame resistance of modules, and in applications involving magnetic responsiveness. ${ }^{13-15}$

Nanofillers also have several significant disadvantages. Many nanoparticles possess high specific surface areas, which make it difficult to suppress particle aggregation. ${ }^{16-18}$ The ability of these nanoparticles to disperse must be improved by methods such as surface treatments, which is a barrier to further research and development. ${ }^{19-21}$

This review focuses on gels (hereafter called supramolecular gels) that can manifest supramolecular functionality through molecular orientation when used as bottom-up nanofillers. We review their use in improving the functionality of transparent polymer materials. Supramolecular gels allow new functionality to be introduced into polymer materials by forming a gel network while maintaining transparency. In this review, we discuss concepts and methods for manufacturing supramolecular gels, their optical characteristics and their applications as optical materials.

\section{SUPRAMOLECULAR GELS}

Polymer gels can exhibit a state in which a three-dimensional network structure forms. This is caused by the cross-linking of polymer chains in liquid media (Figure 1a). The solvent is encapsulated within the three-dimensional network structure, which results in low fluidity and the so-called gel state. In contrast, the gels discussed in this review are in a gel state primarily consisting of low-molecular-weight molecules. Figure $1 \mathrm{~b}$ shows how such molecules produce fibrous aggregates.

${ }^{1}$ Department of Applied Chemistry and Biochemistry, Kumamoto University, Kumamoto, Japan and ${ }^{2}$ Kumamoto Institute for Photo-Electro Organics (PHOENICS), Kumamoto, Japan

Correspondence: Professor H Ihara, Department of Applied Chemistry and Biochemistry, Kumamoto University, 2-39-1 Kurokami, Chuo-ku, Kumamoto 860-8555, Japan. E-mail: ihara@kumamoto-u.ac.jp

Received 30 December 2015; revised 27 March 2016; accepted 29 March 2016; published online 1 June 2016 
a
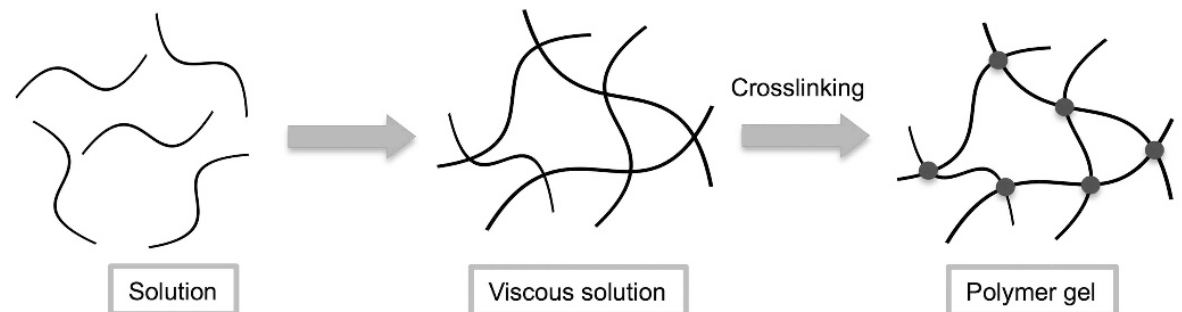

olution

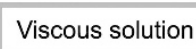

Polymer gel

b
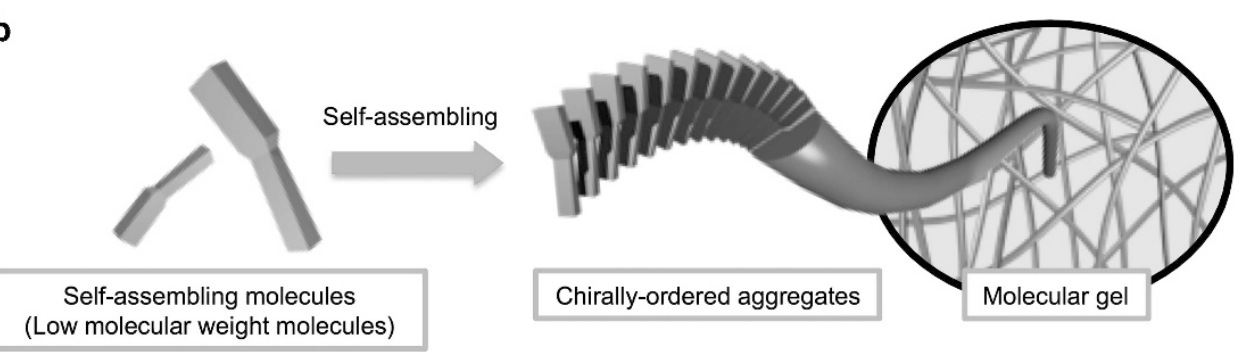

Figure 1 Schematic illustrations of a polymer gel (a) and molecular gel (b). A full color version of this figure is available at Polymer Journal online.

These aggregates develop and interweave into a polymer gel-like three-dimensional network structure, thus forming a gel state. The gathering of these molecules with low molecular weight leads to supramolecular functionality; thus, these gels are often referred to as supramolecular gels. The intended uses of polymer and supramolecular gels often differ greatly. In the former, it is important to be a physical gel state and enclose the solvents in their network structure. The absorbents used in paper diapers are polymer materials that can realize such a state. In supramolecular gels, increasing fibrous aggregation causes the interweaving fibers to form a gel state. However, their main functionality is the supramolecular functionality arising from low-molecular weight-compounds forming a highly ordered structure. This is in contrast to the functionality arising from the physical gel state. Supramolecular gels involve a minimum concentration required to form a physical gel state, which is known as the critical gelation concentration. ${ }^{22}$ However, supramolecular gels visually appear to be in a solution state at concentrations below this and thus are often referred to as manifesting supramolecular functionality. This is because there is generally a minimum concentration required for molecules to aggregate, known as the minimum aggregation concentration. This is lower than the critical gelation concentration and is similar to the critical micelle concentration recognized in surfactants and lipids.

There is no physical necessity for a substance forming a supramolecular gel to be of low molecular weight. However, low-molecular-weight substances possess advantages because of the freedom of their molecular design and their ease of synthesis and purification. For molecules with low molecular weight to gather in solution and reach a gel state, the following are necessary: (1) a region providing suitable interaction between molecules; (2) a region providing compatibility for dispersion in the solvent; and (3) a structure with a mechanism for easily forming a one-dimensional aggregation state (fibrous aggregation). The low-molecular-weight gels that have most profoundly been developed in this research field are the cholesterol derivatives reported by Weiss et al. ${ }^{23,24}$ However, the synthetic bilayer membranes reported by Kunitake et al. ${ }^{25}$ were perhaps more pioneering with respect to fibrous aggregates in diluted solvent, but the authors did not allude to the visual gel state. Fibrous aggregations of several hundred million Dalton molecules reportedly formed as part of the synthetic bilayer membrane. ${ }^{26}$
Substances other than cholesterol derivatives have since been shown to form low-molecular-weight gels and have been the subject of previous reviews. ${ }^{24,27-29}$ Figure 2 shows low-molecular-weight organogelators that have led to subsequent development.

In this review, we focus on amino-acid-derived supramolecular gelators. They allow for much freedom in molecular design, and functionality is easily introduced. These factors make them more versatile than cholesterol- or sugar-based derivatives. For example, multiple amide bonds can be introduced into glutamic acid. This can promote intermolecular interactions through one amino group and two carboxyl groups or various functionalities through the amino group. Hereafter, we refer to the glutamic acid derivatives as glutamides (denoted $G$ in the chemical formula shown in Figure 3). These convenient amino acids include aspartic acid, $\gamma$-aminoadipic acid, ornithine and lysine.

As shown in Figure 3, supramolecular functionality produced by glutamides can be developed in various ways according to the type of functionality. ${ }^{22,30-43}$ When the functional group is hydrophilic, such as an amino $\left(G-\mathrm{C}_{2}-\mathrm{NH}_{2}\right)$ or pyridinium $\left(G-\mathrm{C}_{2}-\mathrm{Py}^{+}\right)$group (Figure 3$)$, the glutamide will form tubular and helical bilayer membranes in polar solvents such as water ${ }^{31,44-46}$ and acetonitrile. ${ }^{46}$ However, the glutamide forms fibrous aggregates in nonpolar solvents such as benzene, and the solution gels at concentrations above the critical gelation concentration. ${ }^{22,47}$ Figure 4 shows aggregates formed from various glutamides. ${ }^{22,30,39,44-46,48-50}$ A feature of the glutamide supramolecular gelator is that the aggregate form changes with molecular structure and with external factors such as the type and temperature of the solvent. This characteristic can be used to modify the aggregate form or supramolecular functionality.

\section{OPTICAL CHARACTERISTICS OF SUPRAMOLECULAR GELS}

Supramolecular functionality using the glutamide derivatives can be observed when introducing functional groups with optical activity (detailed in the following section). Here, we provide an example of a pyrene derivative and an introduced fluorescent dye (Figure 5a, $\mathrm{G}-\mathrm{C}_{3}$-Pyr). $\mathrm{G}-\mathrm{C}_{3}$-Pyr is a hydrophobic compound with a fluorophore group. It is insoluble in water but soluble in many organic solvents. Dissolving $\mathrm{G}_{-} \mathrm{C}_{3}-\mathrm{Pyr}$ in heated cyclohexane or toluene at a concentration of approximately $5 \mathrm{~mm}$ and then returning it to room temperature yields a transparent gel. Transmission electron microscopy 
<smiles>[R]NC(=O)CCCN([2H])C(=O)CCNNC(=O)OCc1ccccc1</smiles><smiles>CCCC1CCC2C1CCC1C2CC=C2C[C@@H](CC(=O)CCCOc3ccc4cc5ccccc5cc4c3)CCC21C</smiles>

C<smiles>[R]Oc1cc2cc3ccccc3cc2cc1O[2H]</smiles>

d

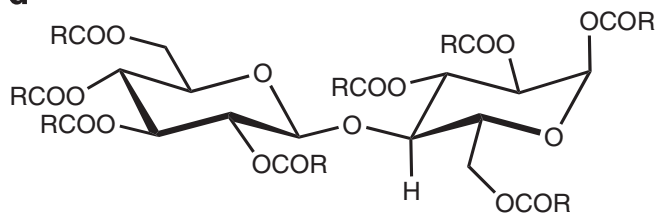

Figure 2 Structures of gel-forming low-molecular-weight compounds: (a) amino acid-based, (b) cholesterol-based, (c) polyaromatic-based and (d) sugar-based derivatives.

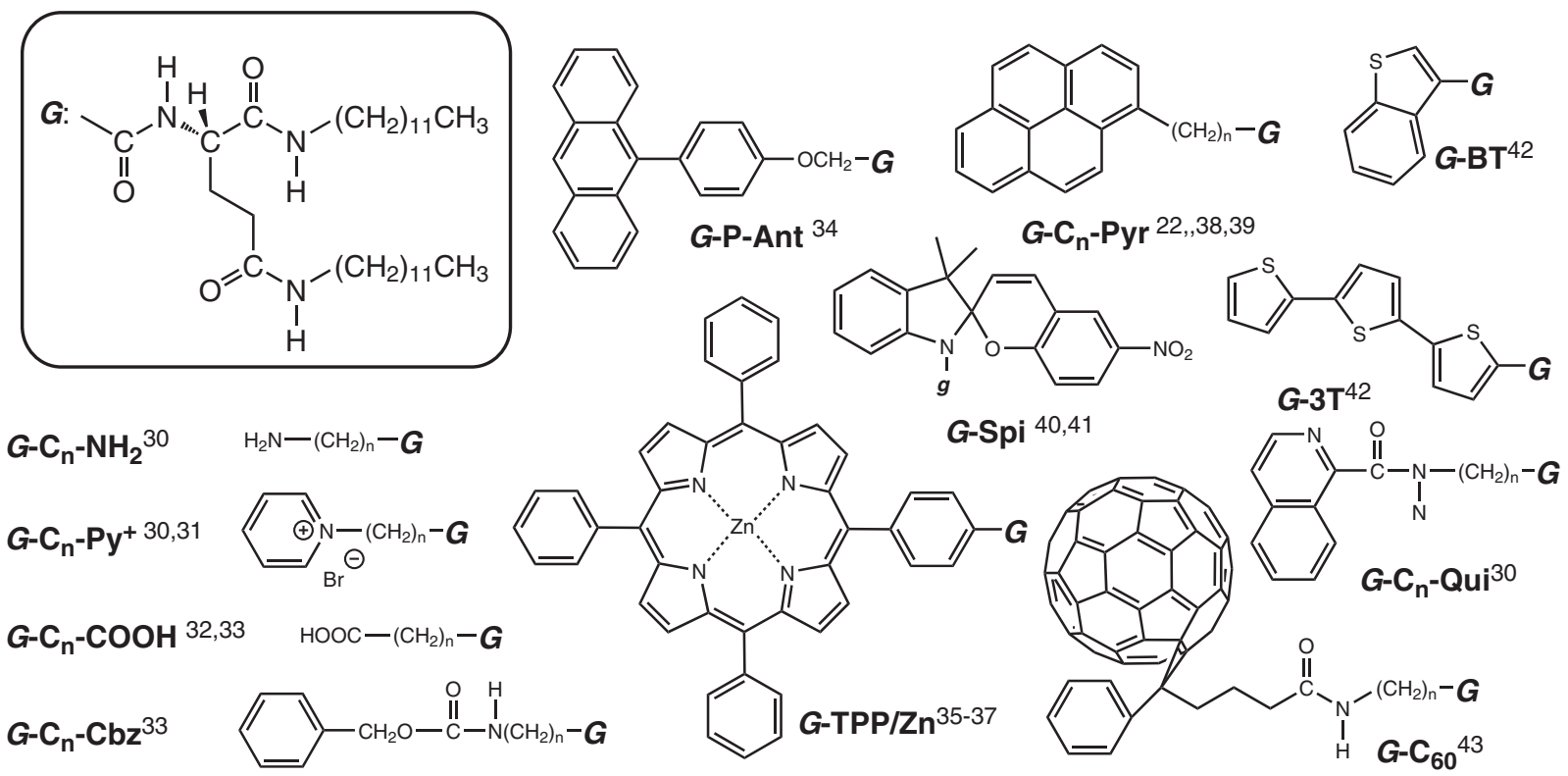

Figure 3 Structures of glutamide-based gel-forming compounds with various functional groups.

images show that the gel contains fibrous aggregates. Fluorescence spectroscopy provides further information about its molecular orientation. When $\mathrm{G}-\mathrm{C}_{3}-\mathrm{Pyr}$ in benzene at $25^{\circ} \mathrm{C}$ is excited at $350 \mathrm{~nm}$, the pyrene excimer fluoresces with a maximum at $455 \mathrm{~nm}$. This is not observed for the starting materials pyrenebutanoic acid and estertype $\mathrm{Ge}_{-} \mathrm{C}_{3}$-Pyr, which only weakly aggregate. No excimer emission is observed above $60{ }^{\circ} \mathrm{C}$, the point at which $G-\mathrm{C}_{3}$-Pyr disassociates.

Similar to $\mathrm{G}_{-} \mathrm{C}_{3}-\mathrm{Pyr}$, non-glutamide derivatives with fluorophores have also been investigated by other groups. Figure 6 summarizes typical examples of supramolecular gel-forming fluorophores in organic solvents. Figure 6 a shows an organogelator based on a salicylideneaniline derivative with cholesterol moieties, which self-assembles into a three-dimensional fibrous network. ${ }^{51}$ The benzene/cyclohexane gel emits bright green light with a Stokes shift of $177 \mathrm{~nm}$. This indicates that emission arises from excited state intramolecular proton transfer luminescence. The fluorescence intensity of the gel is more than 1000 times higher than that in solution because of the formation of J-aggregates and restricted intramolecular rotation. The molecular combination of two $N$-lauroyl phenylalanine and one 1,4-bis(2-(pyridin-4-yl)vinyl)-benzene moieties 

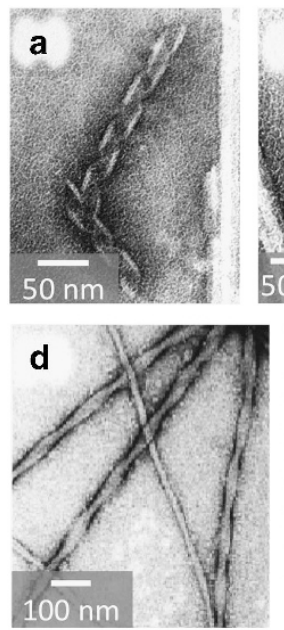
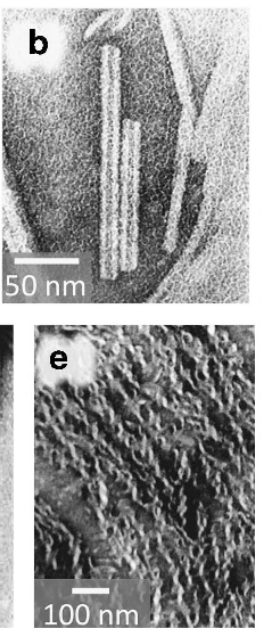

In water
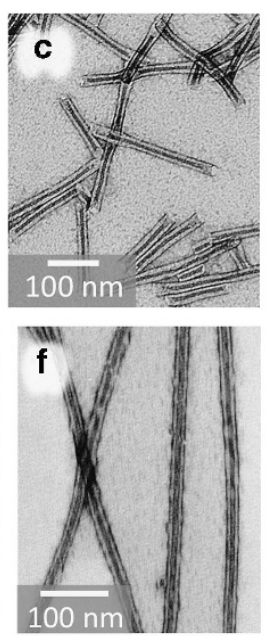
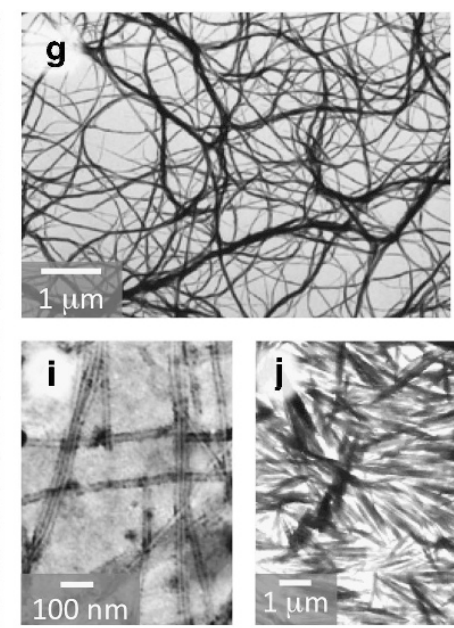

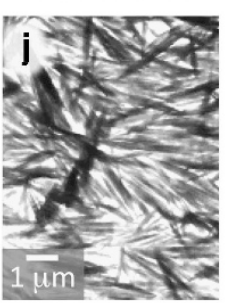

In organic solvent
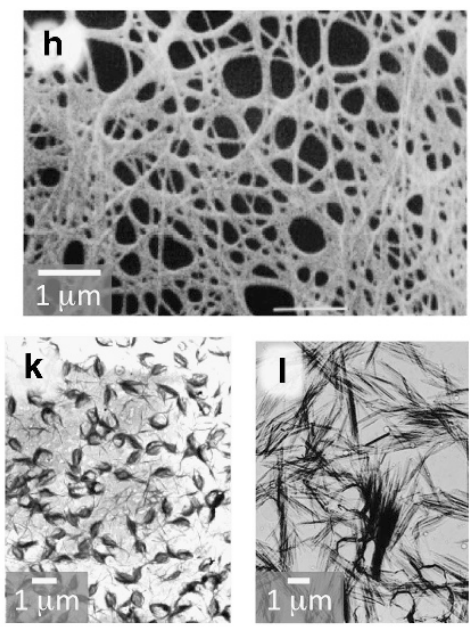

1 um 1 ? 2 .

Figure 4 Electron microscopy images of nanofibril aggregates from various glutamides in aqueous $(\mathbf{a}-\mathbf{f})^{44,46,48,49}$ and organic (g-l) media. ${ }^{22,30,39,45,50}$

a

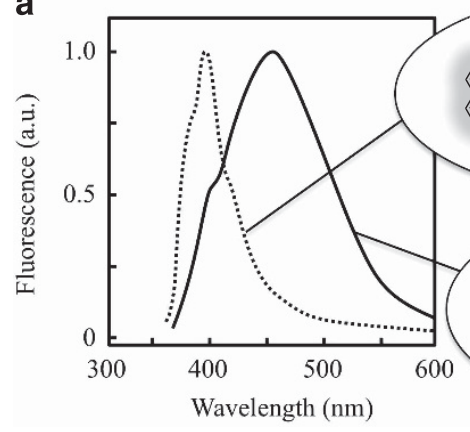

b

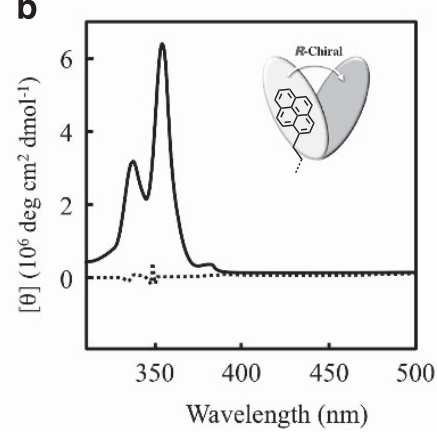

Figure 5 Fluorescence (a) and $C D$ (b) spectra of $G-C_{3}-P y r$ (solid) and $G e-C_{3}-P y r$ (dotted) in cyclohexane. A full color version of this figure is available at Polymer Journal online.

G-C - Pyr: $X=N H, G_{-}-C_{3}-P y r: X=0$.

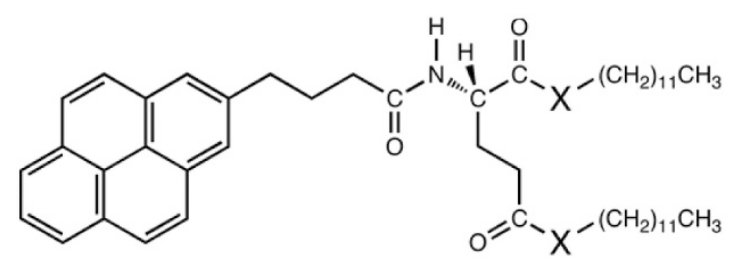

(Figure 6b) also exhibits gelation with nanofibers. ${ }^{52} \mathrm{~A}$ hot solution in cyclohexane emits strong blue fluorescence, whereas the gel exhibits enhanced yellow emission. These gel-phase nanofibers have been applied to detect organic amine vapor in fibrous films. Emission changes from yellow to blue upon exposure to aliphatic amines. The L-phenylalanine derivative with 5,8-bis[2-(carbazol-3-yl)]-2, 3 -dimethylquinoxaline (DCQ) moieties (Figure $6 \mathrm{c})^{53}$ reportedly gels in some organic solvents and self-assembles into one-dimensional nanofibers in gels. The DCQ gel exhibits enhanced green fluorescence compared with its heated solution. DCQ gel films also exhibit strong fluorescence and have been used to detect trifluoroacetic, hydrochloric and acetic acids. The reported detection limits of DCQ thin films for these three volatile acids are 43, 122 and $950 \mathrm{ppb}$, respectively.

The orientation and aggregation states of $G-\mathrm{C}_{3}-\mathrm{Pyr}$ can be estimated using circular dichroism (CD) spectroscopy. ${ }^{54}$ Figure $5 \mathrm{~b}$ shows the $\mathrm{CD}$ spectra of $G-C_{3}$-Pyr and $G e-C_{3}$-Pyr. $G-C_{3}-P y r$ can form an excimer, and its $\mathrm{CD}$ spectrum exhibits a strong positive signal due to the Cotton effect. The pyrenyl group contains no chirality, so chirality is induced from the glutamide to pyrenyl groups. This is referred to as induced chirality, and the resulting CD is referred to as induced CD. The orientation state of the pyrenyl group can be estimated from the induced CD spectrum (Figure $5 \mathrm{~b}$ inset) using Davydov splitting theory. ${ }^{55}$ Figure 5 shows the resulting estimated orientation state.

One advantage of glutamides is that various functional groups can be introduced. G-TPP can aggregate and orientate in solution, even when it contains large tetraphenylporphyrin groups. G-TPP/Zn is a glutamide derivative with a zinc-inserted tetraphenylporphyrin moiety. ${ }^{36,50}$ When $G$-TPP/Zn is dissolved in cyclohexane and pyridine or its derivatives are selected as an axial ligand, a particular CD pattern can be observed (Figure 7). ${ }^{50}$ Such changes are not observed during 

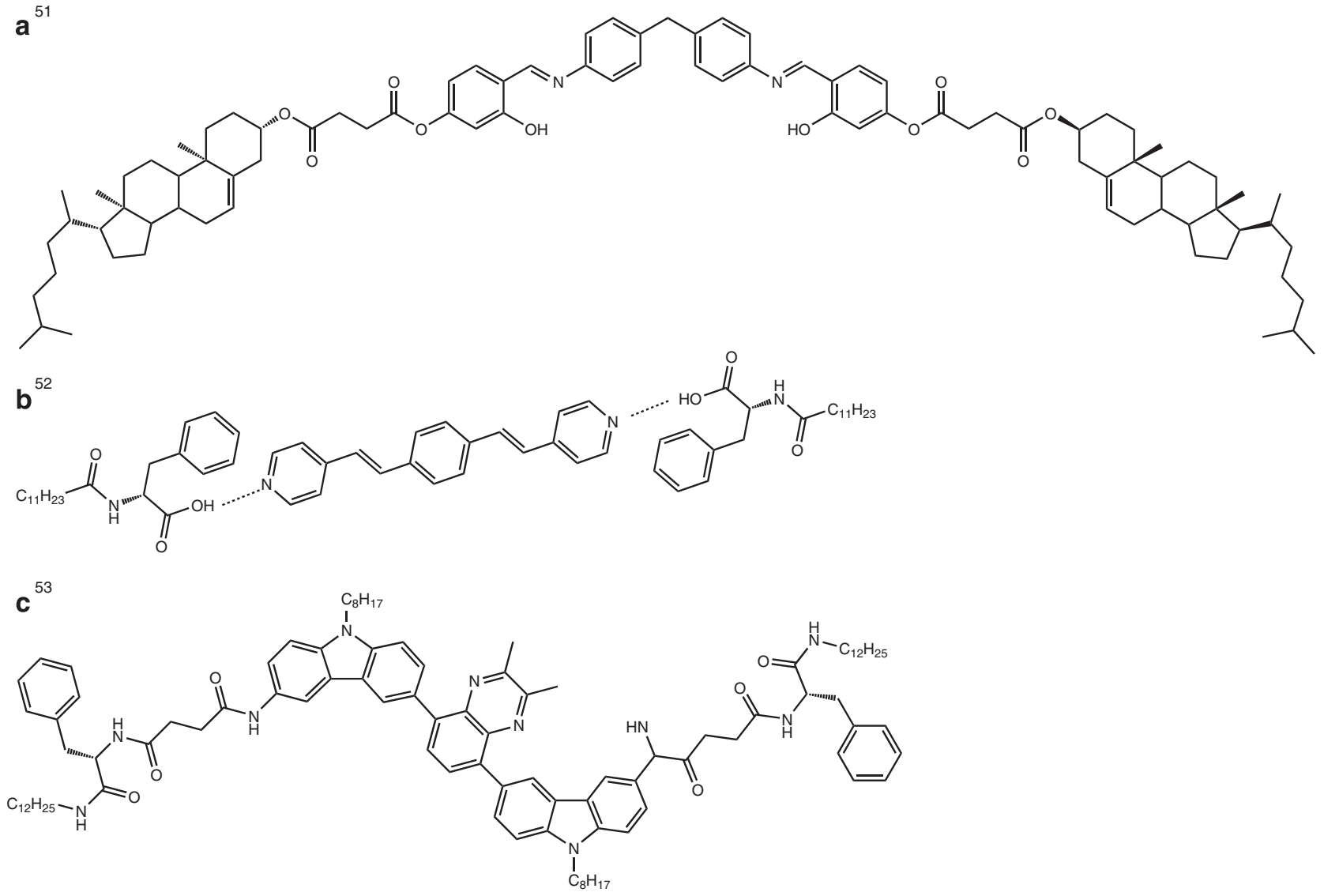

Figure 6 Structures of low-molecular-weight gel-forming fluorophores. ${ }^{51-53}$

the non-aggregated state and are thought to result from the axial ligand perturbing the stacking (for example, angle, distance, number of aggregates, so on). Such changes in chirality can also be applied to the optical resolution of amino acids. ${ }^{56}$ We previously reported the concentrated orientation of fullerenes using pyridyl groups. The resulting system exhibits high electronic transfer efficiency (Figure 8).

The optical characteristics of glutamide derivatives are further emphasized by their circularly polarized luminescence (CPL) ${ }^{34}$ These have been touted as next-generation light sources, and the $\mathrm{G}_{-} \mathrm{C}_{3}-\mathrm{Pyr}$ system is particularly promising in this regard. The L-isomer of $G-C_{3}$-Pyr provides CPL with negative signals around an emission band of excimeric pyrene, with the D-isomer providing the opposite signal (Figure 9a). The glutamide system also exhibits induced CPL, known as iCPL. Figure 9b shows that the helical bilayer membrane formed from $\mathrm{G}-\mathrm{C}_{2}-\mathrm{Py}^{+}$results in iCPL for non-chiral and nonfunctionalized anthracene. Similar iCPL is also observed for small fluorophores such as pyrene and fluorene, but not for bulky ones such as diphenylanthracene. ${ }^{57,58}$ This is the first report of CPL resulting from simple non-chiral fluorophores.

POLYMER FUNCTIONALIZATION BY SUPRAMOLECULAR GELS There are some examples of supramolecular gels being used for polymer functionalization. Here, we introduce an example of a supramolecular gel being used as a bottom-up nanofiller for functionalizing polymer materials. $G-C_{3}$-Pyr can be used for gelation with various polymerizable solvents, as shown in the transmission electron microscopy images in Figure $10^{39}$. This indicates that supramolecular gels can be formed in polymerizable monomers. Incorporating $1 \mathrm{wt} \% \quad G-\mathrm{C}_{3}-\mathrm{Pyr}$ into methyl methacrylate in the presence of a suitable photosensitizer and subsequent photopolymerization in the cell at $0{ }^{\circ} \mathrm{C}$ yields a transparent solid thin film with a large $\mathrm{CD}$ signal. This indicates that the chiral orientation of the pyrenyl group can be observed. ${ }^{39}$ The strength and pattern are similar to those before polymerization, indicating that the chiral orientation of $\mathrm{G}-\mathrm{C}_{3}$-Pyr is fixed in the solid thin film. Photopolymerization at $70{ }^{\circ} \mathrm{C}$ yields a similar colorless transparent solid thin membrane that exhibits almost no CD signal. These results indicate that the specific oriented states of $G-C_{3}-P y r$ can be fixed in the polymer, that is, the polymer state has been memorized. Even when a fixed thin film created at $0{ }^{\circ} \mathrm{C}$ is heated to $70^{\circ} \mathrm{C}$, no significant change in the $\mathrm{CD}$ signal is observed. It is clear that heat stability is improved by encapsulating $\mathrm{G}_{-} \mathrm{C}_{3}-\mathrm{Pyr}$ aggregates into the polymer. ${ }^{39}$

A simple method of producing these composite polymer films is by casting from a polymer solution containing the glutamide. Mixed gels containing bulk polymers can be produced, with subsequent casting and drying producing transparent films. Polystyrene, polymethyl methacrylate and poly(ethylene-vinyl acetate) (EVA) copolymers have all been used as bulk polymers. ${ }^{37,39,59}$ Figure 11a shows the CD and fluorescence spectra of films produced by cast-coating from a solution containing $\mathrm{G}_{-} \mathrm{C}_{3}$-Pyr and Polystyrene. These spectra show excimeric emission and strong CD similar to those in solution systems. These results suggest that chirally ordered states can be reproduced by casting. ${ }^{37}$

Casting also allows functional dyes to be added as chromophores. Figure $11 \mathrm{~b}$ shows the $\mathrm{CD}$ spectra of an anionic glutamide $\left(G-\mathrm{C}_{3}-\mathrm{COOH}\right.$, Figure 3) used as a supramolecular gel. Blending cationic dyes with the $\mathrm{G}-\mathrm{C}_{3}-\mathrm{COOH}$-polymer system yields cast films that are colored but transparent. Figure $11 \mathrm{~b}$ shows that the dye-doped 

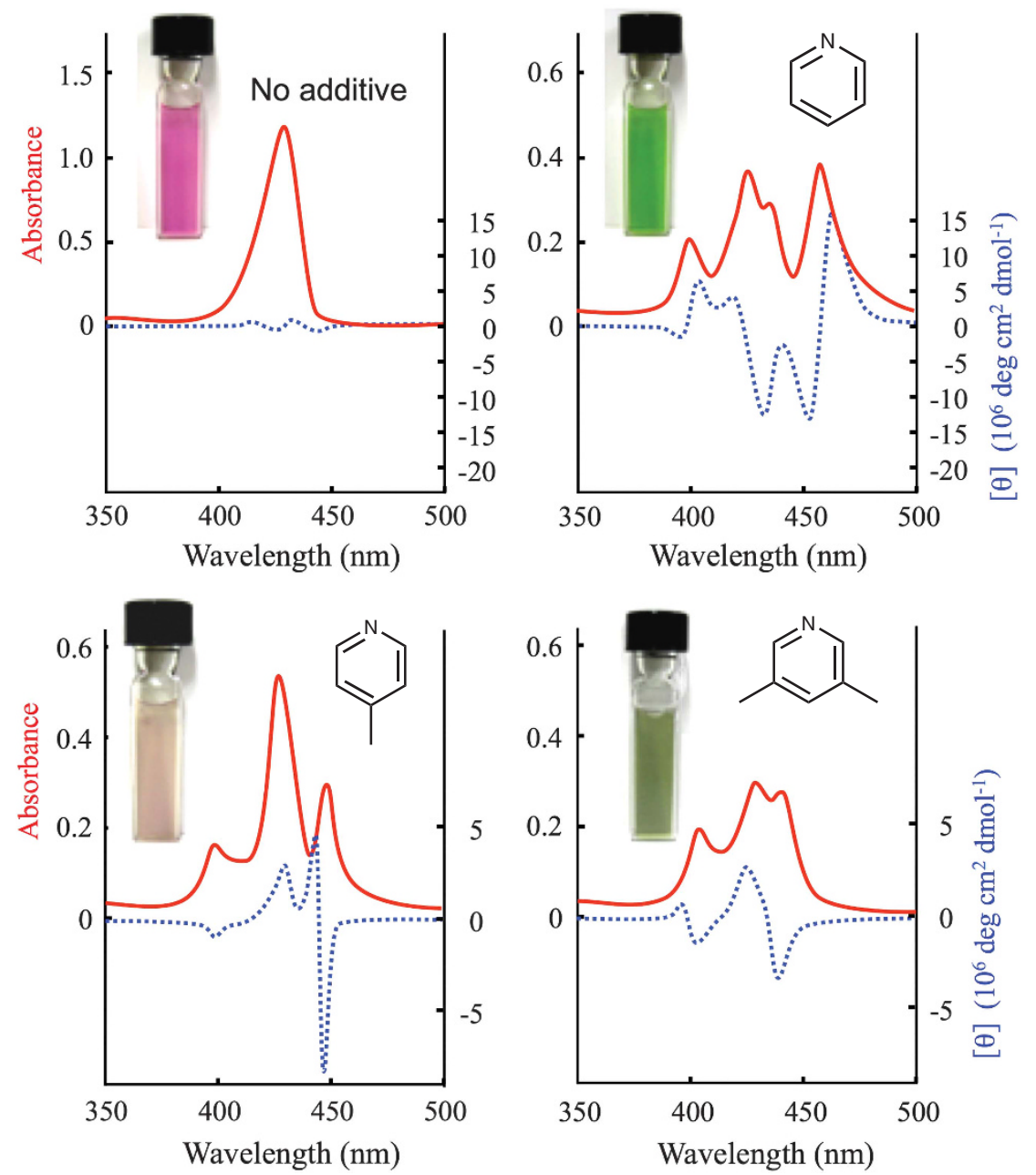

Figure 7 Ultraviolet-visible absorption (solid) and circular dichroism (dotted) spectra of G-TPP/Zn ( $0.25 \mathrm{mm)}$ containing 10 equivalents of various pyridine derivatives in cyclohexane at $20^{\circ} \mathrm{C}$.

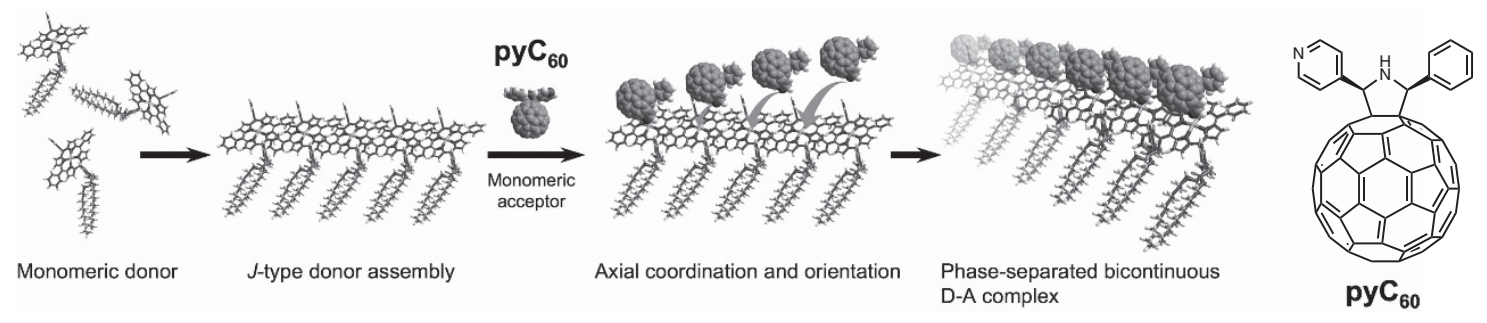

Figure 8 Schematic illustration of a phase-separated donor-acceptor system consisting of G-TPP/Zn and pyC $\mathrm{C}_{60}$. A full color version of this figure is available at Polymer Journal online.

polymer gel film exhibits specific $\mathrm{CD}$ patterns based on each absorption band. The doped dyes are all non-chiral, so the CD signals are induced CD generated by statically bound chirally orientated glutamide aggregates in the polymer film. ${ }^{32}$ The induced CD of the dye-supramolecular gel-polymer could potentially be further improved using technology that increases the freedom of its functional design as an optical film.

The fibrous aggregation of glutamides in polymers can be observed using electron microscopy. ${ }^{59,60}$ Figure 12 shows that dying EVA films containing $G-C_{3}-\mathrm{Pyr}$ using an osmium plasma coater form fibrous aggregates with diameters of $10 \mathrm{~nm}$ or less in the EVA film.
Aggregated states can also be observed using conventional heavy metal staining agents when forming composites with high-polarity amphiphilic glutamide derivatives. Figure 12 shows that $G-\mathrm{C}_{2}-\mathrm{Py}^{+}$is formed of helical aggregates with the polyvinylpyrrolidone.

\section{DEVELOPMENT OF OPTICAL MODULATORS}

Solar light and various artificial light sources often do not contain the most suitable wavelengths or intensities for a given purpose. Light management can be achieved through shielding, wavelength cutting, polarization and wavelength selective reflection. ${ }^{61,62}$ Silicon solar batteries have a low optical sensitivity to ultraviolet (UV) light. The 

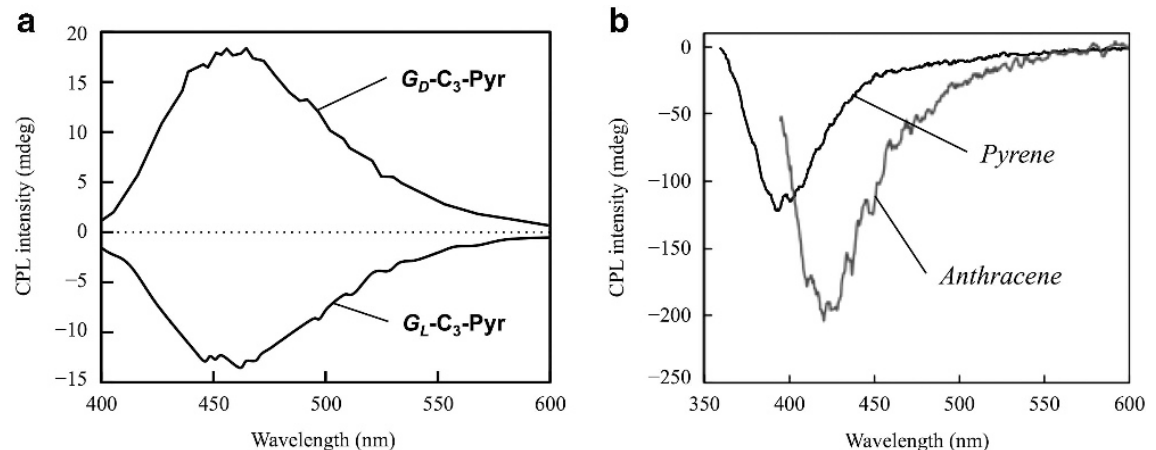

Figure 9 Circularly polarized luminescence (CPL) spectra of $G-C_{3}-$ Pyr isomers in polyvinyl alcohol (PVA) film (a) and luminescent pyrene and anthracene on $G-C_{2}-P^{+}$aggregates in aqueous solution (b). $\lambda_{\mathrm{ex}}=330 \mathrm{~nm}$ (a), $320 \mathrm{~nm}$ for pyrene and $340 \mathrm{~nm}$ for anthracene (b).
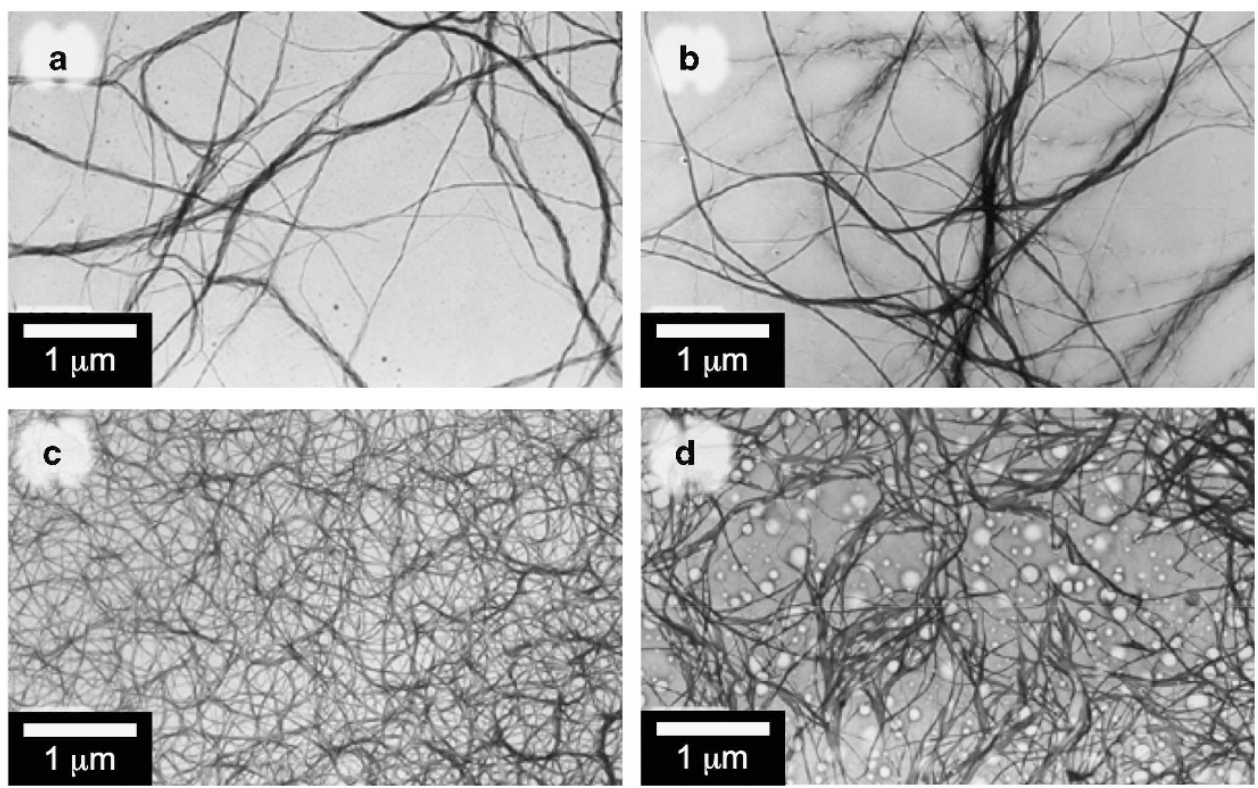

Figure 10 Transmission electron microscopy images of $G-C_{3}-P y r$ in styrene (a), divinylbenzene (b), methyl methacrylate (c) and methacrylate (d). $\left[G-C_{3}-P y r\right]=1 \mathrm{~mm}$

incident energy level is relatively high, so the UV component is often removed using glass filters. The solar spectrum also contains a large portion of unused infrared wavelengths. Dyes for dye-sensitized solar cells have been developed to better harvest infrared wavelengths. Similarly, most artificial light sources contain unused wavelengths. More efficient use of these wavelengths will be an important issue in the future.

The simplest methods in light management are cutout and polarizing filters. Technologies for converting UV and infrared wavelengths to visible wavelengths in common living environments are required to efficiently use all incident light. Fluorescent materials containing rare-earth elements are the most advanced in this respect. Converting UV wavelengths to visible wavelengths has mainly involved nitrite- or garnet-based rare-earth compounds. $\mathrm{Eu}^{2+}$ and $\mathrm{Ce}^{3+}$ have been used as activators in light-emitting materials for lamps, lighting and white light-emitting diodes. Up-conversion from infrared light has been achieved using fluoride- or oxide-containing lanthanides, such as $\mathrm{Er}^{3+}, \mathrm{Yb}^{3+}$ or $\mathrm{Tm}^{3+} .63$ Their application has spread to photovoltaic cells and light-emitting materials for biosensing. ${ }^{64-69}$
There have recently been calls to refrain from using rare-earth compounds and strong demands for all- organic systems that can control various functions. Many materials exhibiting high Stokes shifts required for wavelength conversion have been reported. ${ }^{30,37,38,59,70-72}$ In this section, we discuss the application of a luminescent supramolecular gel as an organic fluorescent system.

Supramolecular gels do not rely on the chemical structure of the doped dye for the Stokes shift. The Stokes shift of such gels can be controlled by the orientation state between dyes. For glutamides, Stokes shifts of approximately 100 and $170 \mathrm{~nm}$ can be obtained with pyrene $e^{38}$ and anthracene, ${ }^{34}$ respectively. Figure 13 shows a G-C ${ }_{3}$-Pyr-containing EVA composite applied to the surface of a CIGS (copper indium gallium diselenide)-type photovoltaic cell (Honda Soltec Co., Ltd, Kumamoto, Japan). The result of this system was compared with the conversion rate of simulated solar light (AM1.5). Figure 13 shows that it emits blue light because of the projection of UV light on the solar power battery coated with the glutamide gel. Measurement was performed on a $5 \times 5 \mathrm{~cm}^{2}$ region in the center of the cell. The power generation efficiency of $15 \%$ before coating increased to $15.8 \%$ after coating. This is attributed to the 


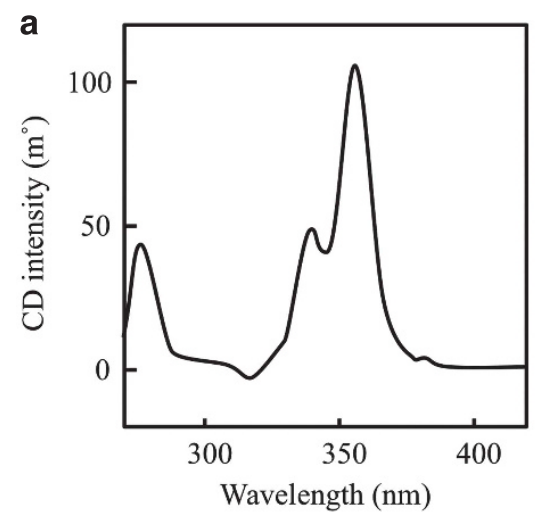

b
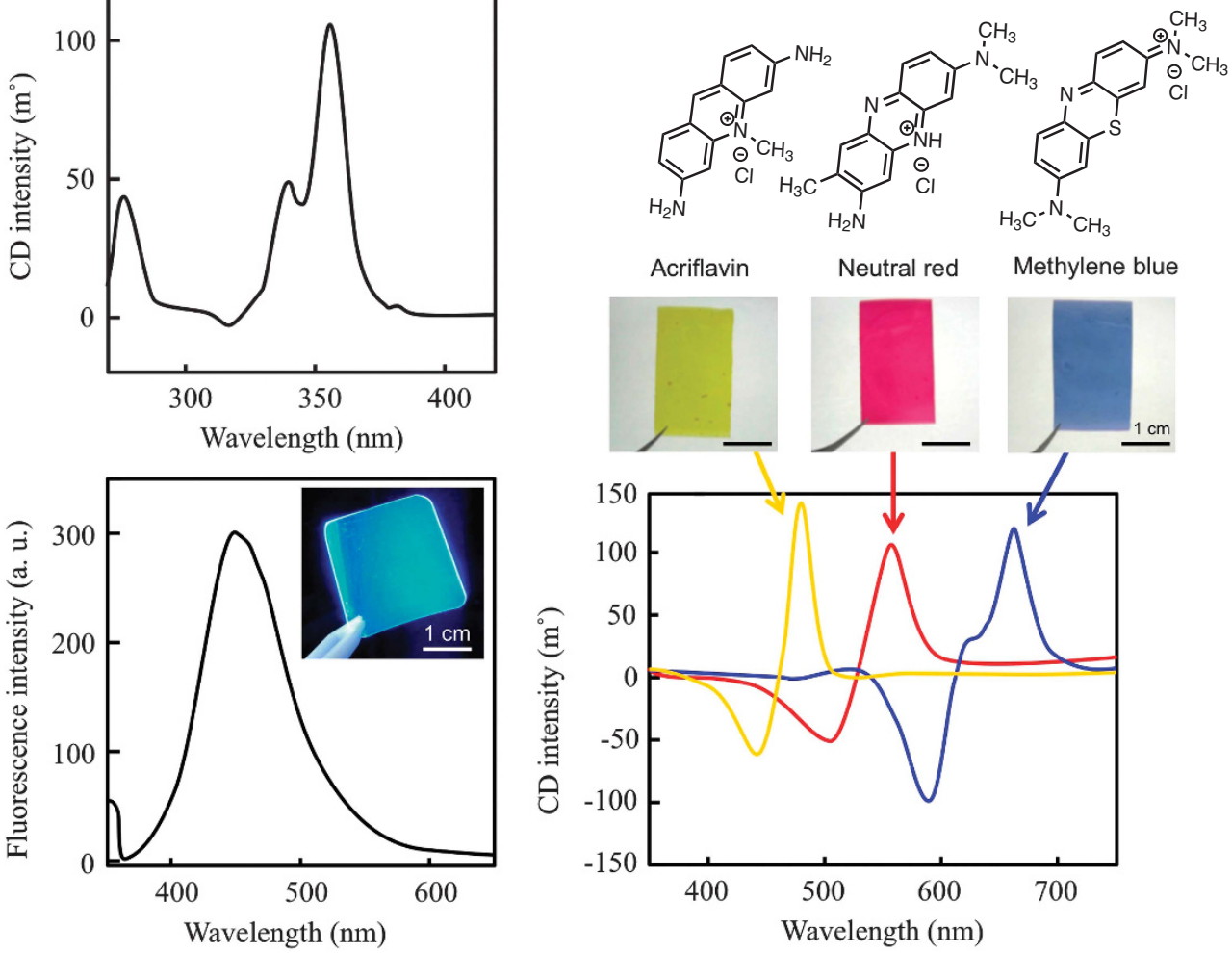

Figure 11 Circular dichroism (CD) and fluorescence spectra of a $G-C_{3}-$ Pyr/PSt [1:99 (wt/wt)] cast film (a) and $C D$ spectra of cationic dyes with $G$ - $\mathrm{C}_{3}-\mathrm{COOH}$ aggregates in polystyrene (PSt) films (b).
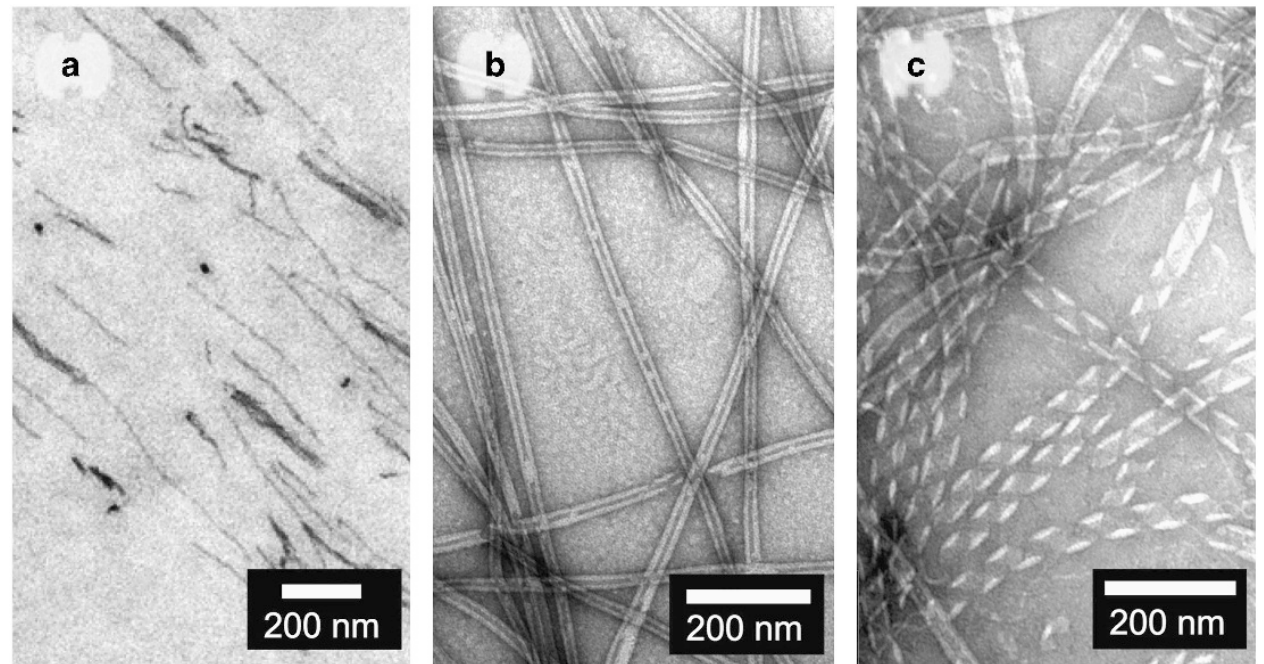

Figure 12 Transmission electron microscopy images of $G-C_{3}-P y r$ aggregates in poly(ethylene-vinyl acetate) (a) and $G-C_{2}-P y^{+}$aggregated in polyvinyl pyrrolidone ( $\mathbf{b}$ and $\mathbf{c}$ ). Staining by Ru(II) tetraacetate (a) and uranyl acetate ( $\mathbf{b}$ and $\mathbf{c}$ ).

supramolecular gel absorbing UV light with low spectral sensitivity and converting it to visible wavelengths with high spectral sensitivity (excimer emission occurs at $460 \mathrm{~nm}){ }^{59}$

Constructing energy transfer systems with other dyes can produce transparent films with various emission bands. Figure 14 shows a CIExy chromaticity diagram ${ }^{59}$ and coordinates for EVA films containing coumarin, Nile red and rubrene, as well as the $G-C_{3}-\mathrm{Pyr}$ system. The composition and wavelength both significantly change with temperature. This is thought to be due to differing energy transfer rates between the doped dyes and changes in the $\mathrm{G}_{-} \mathrm{C}_{3}-\mathrm{Pyr}$ monomer/excimer ratio. Such significant changes in emission wavelength are not observed for pyrene, which does not contain glutamide.

Various living organism-related molecules possess optical activity (chirality). Their existence affects the basis of life phenomena. For this 


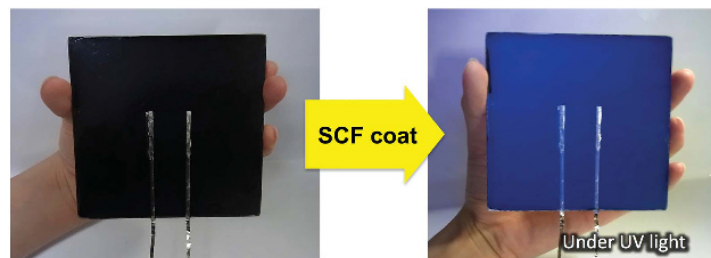

Figure $13 \mathrm{CIGS}$ solar cell before and after coating with a spectral conversion film (SCF). The power conversion efficiency was improved from 15.0 to $15.8 \%$ by using the SCF. Efficiencies were measured for a $5 \times 5 \mathrm{~cm}^{2}$ region at the center of the cell.

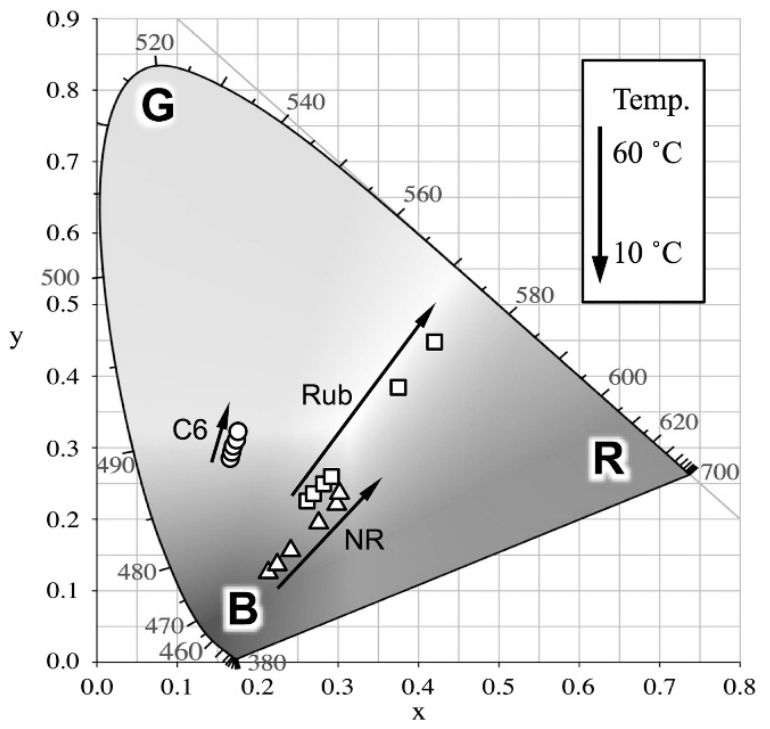

Figure 14 Temperature-dependent corresponding CIE 1931 chromaticity coordinates of $G-C_{3}$-Pyr $(0.5 \mathrm{~mm}$ ) with acceptor dyes, EVA40 (5 wt\%) with acceptor dyes and EVA40 (5 wt\%) in 1:1 toluene:ethyl acetate. Acceptor concentrations: coumarin6 (C6, $4 \mathrm{~mol} \%$ ), Nile red (NR, $10 \mathrm{~mol} \%$ ) and rubrene (Rub, $200 \mathrm{~mol} \%$ ). Arrows indicate the temperature change from 10 to $60^{\circ} \mathrm{C}$. A full color version of this figure is available at Polymer Journal online.

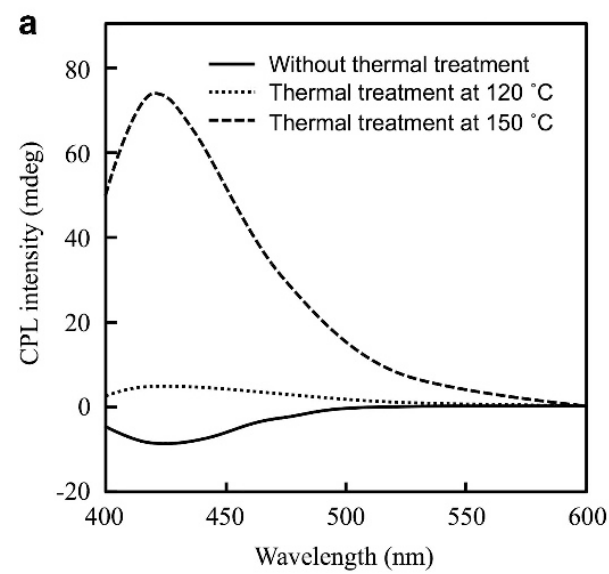

b

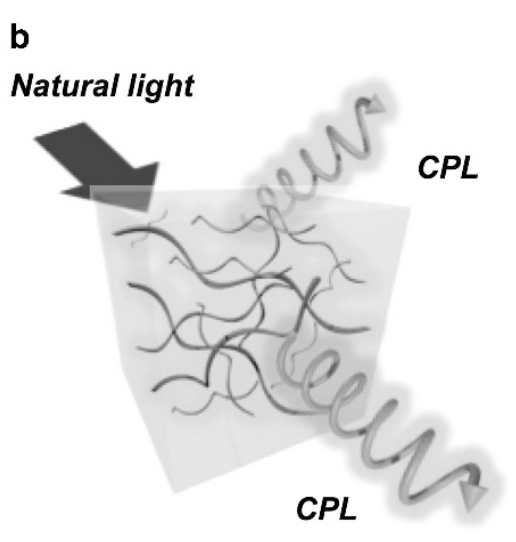

Figure 15 Circularly polarized luminescence (CPL) spectra of $G-C_{0}-P y r$ in poly(ethylene-vinyl acetate) with and without thermal treatment (a) and a schematic illustration of a self-assembled nanofiber-containing polymer composite film exhibiting CPL (b). A full color version of this figure is available at Polymer Journal online.

reason, distinguishing polarization characteristics is an important ability for living things. There has been much recent research and development of CPL materials. ${ }^{73-77} \mathrm{CPL}$ is expected to be applied in display materials, optical recording devices, sensors, biological probes and optical media. CPL can reportedly be generated from fluorescent dyes spatially fixed in cyclodextrin. ${ }^{78,79}$ There are reports of CPL from chiral metal complexes, helical polymers, chiral liquid crystals and other chiral organic systems. ${ }^{80-85}$

Chirality produced from supramolecular gels differs from molecular chirality. The former possesses a secondary chirality due to the chiral stacking of molecules and thus exhibits a much larger cotton effect (CD signal) than molecular chirality. There are high expectations for its use in optically active filters. The luminescent group does not need to be chiral, which greatly increases the freedom of molecular design. Figure 15 shows the CPL spectra of a transparent film produced from $G-C_{0}-P y r$ and EVA. The light emission band matches that of the $G-\mathrm{C}_{0}$-Pyr excimer, which suggests that this is CPL based on chiral stacking (secondary chirality) of the pyrenyl group. ${ }^{57,86}$ The CPL intensity is greatly affected by heat-treating the polymer film because it greatly affects the physical state of the bulk polymers. There are high expectations for the development of CPL-generating films containing luminescent supramolecular gels.

\section{CONCLUSIONS}

We have provided an overview of luminescent supramolecular gels. We have also explained the principles of their optical characteristics, the compounding of polymers and their applications. It is unlikely that the same level of durability will be achieved for supramolecular gels based on organic materials as for those based on inorganic materials. However, the advantages of all organic materials include their light weight, flexibility, excellent processability and high degree of freedom with respect to functional design. We conclude by summarizing the merits of supramolecular gels.

Supramolecular gels provide compatibility between polymers and polymer solutions based on their design. It is possible to apply a process free of dispersants when forming a composite, which simplifies handling. Such dispersants can have negative effects on polymers. Specially designed materials such as block polymers are not required for the bulk polymer. Thus, supramolecular gels can be formed from generic polymers. 
The gel-forming molecules form self-organized nanofibers in the polymer. There is nothing to cause whitening from secondary aggregation,which often occurs in metal oxide nanoparticles. Thus, it is easy to maintain transparency even after forming the polymer composites.

The gel-forming molecules are phase separated when forming the orientated structure in the polymer. This allows for secondary functionality based on their orientation. The molecular design of the gel-forming compound thus dictates the supramolecular functionalization of the polymer. High Stokes shifts, induced chirality and CPL generation can be imparted as required to the polymer material.

Light management using molecular optical modulators has potential applications in solar-powered batteries, homes, cars and displays, as well as artificial and agricultural lighting. Light management using supramolecular gels through a $G$-tool is well suited to such applications. Various $G$-based luminescent molecules have been widely investigated. ${ }^{87-93}$

\section{CONFLICT OF INTEREST}

The authors declare no conflict of interest.

1 Chau, J. L. H., Lin, Y.-M., Li, A.-K., Su, W.-F., Chang, K.-S., Hsu, S. L.-C. \& Li, T.-L. Transparent high refractive index nanocomposite thin films. Mater. Lett. 61, 2908-2910 (2007).

2 Lu, C. \& Yang, B. High refractive index organic-inorganic nanocomposites: design, synthesis and application. J. Mater. Chem. 19, 2884-2901 (2009).

3 Otsuka, T. \& Chujo, Y. Synthesis of transparent poly(vinylidene fluoride) (PVdF)/ zirconium oxide hybrids without crystallization of PVdF chains. Polymer 50, 3174-3181 (2009).

4 Tamai, T., Watanabe, M., Minami, Y., Okazaki, S., Masuyama, A. \& Matsukawa, K. Polymer particles incorporating $\mathrm{ZrO}_{2}$ nanoparticles prepared by miniemulsion polymerization. Chem. Lett. 40, 37-39 (2011).

5 Wong, M., Guenther, J., Sun, L., Blümel, J., Nishimura, R. \& Sue, H.-J. Synthesis and fabrication of multifunctional nanocomposites: stable dispersions of nanoparticles tethered with short, dense and polydisperse polymer brushes in poly(methyl methacrylate). Adv. Funct. Mater. 22, 3614-3624 (2012).

6 Jintoku, H. \& Ihara, H. The simplest method for fabrication of high refractive index polymer-metal oxide hybrids based on a soap-free process. Chem. Commun. 50, 10611-10614 (2014).

7 Liu, Y. \& Kumar, S. Polymer/carbon nanotube nano composite fibers-a review. ACS Appl. Mater. Interfaces 6, 6069-6087 (2014).

8 Zou, H., Wu, S. \& Shen, J. Polymer/silica nanocomposites: preparation, characterization, properties, and applications. Chem. Rev. 108, 3893-3957 (2008).

9 Gross, S., Camozzo, D., Di Noto, V., Armelao, L. \& Tondello, E. PMMA: a key macromolecular component for dielectric low- $\kappa$ hybrid inorganic-organic polymer films. Eur. Polym. J. 43, 673-696 (2007).

10 Grossiord, N., Loos, J., Regev, O. \& Koning, C. E. Toolbox for dispersing carbon nanotubes into polymers to get conductive nanocomposites. Chem. Mater. 18, 1089-1099 (2006).

11 Simon, P. F. W., Ulrich, R., Spiess, H. W. \& Wiesner, U. Block copolymer-ceramic hybrid materials from organically modified ceramic precursors. Chem. Mater. 13, 3464-3486 (2001).

12 Manias, E., Touny, A., Wu, L., Strawhecker, K., Lu, B. \& Chung, T. C. Polypropylene/ montmorillonite nanocomposites. Review of the synthetic routes and materials properties. Chem. Mater. 13, 3516-3523 (2001).

13 Nowosielski, R., Gramatyka, P., Sakiewicz, P. \& Babilas, R. Ferromagnetic composites with polymer matrix consisted of nanocrystalline Fe-based filler. J. Magn. Magn. Mater. 387, 179-185 (2015).

14 Strawhecker, K. E. \& Manias, E. Structure and properties of poly(vinyl alcohol)/Na+ montmorillonite nanocomposites. Chem. Mater. 12, 2943-2949 (2000).

15 Gangopadhyay, R. \& De, A. Conducting polymer nanocomposites: a brief overview. Chem. Mater. 12, 608-622 (2000).

16 Kodger, T. E. \& Sprakel, J. Thermosensitive molecular, colloidal, and bulk interactions using a simple surfactant. Adv. Funct. Mater. 23, 475-482 (2013).

17 Noor El-Din, M. R., El-Gamal, I. M., El-Hamouly, S. H., Mohamed, H. M., Mishrif, M. R. \& Ragab, A. M. Rheological behavior of water-in-diesel fuel nanoemulsions stabilized by mixed surfactants. Colloid Surf. A 436, 318-324 (2013).

18 Jose, M. \& Sakthivel, M. Synthesis and characterization of silver nanospheres in mixed surfactant solution. Mater. Lett. 117, 78-81 (2014).
19 Min, Y., Akbulut, M., Kristiansen, K., Golan, Y. \& Israelachvili, J. The role of interparticle and external forces in nanoparticle assembly. Nat. Mater. 7, 527-538 (2008).

20 Akcora, P., Liu, H., Kumar, S. K., Moll, J., Li, Y., Benicewicz, B. C., Schadler, L. S., Acehan, D., Panagiotopoulos, A. Z., Pryamitsyn, V., Ganesan, V., Ilavsky, J., Thiyagarajan, P., Colby, R .H. \& Douglas, J. F. Anisotropic self-assembly of spherical polymer-grafted nanoparticles. Nat. Mater. 8, 354-359 (2009).

21 Guo, J., Yang, W. \& Wang, C. Magnetic colloidal supraparticles: design, fabrication and biomedical applications. Adv. Mater. 25, 5196-5214 (2013).

22 Ihara, H., Yoshitake, M., Takafuji, M., Yamada, T., Sagawa, T., Hirayama, C. \& Hachisako, H. Detection of highly oriented aggregation of L-glutamic acid-derived lipids in dilute organic solution. Liq. Cryst. 26, 1021-1027 (1999).

23 Lin, Y. C. \& Weiss, R. G. Liquid-crystalline solvents as mechanistic probes. 24. A novel gelator of organic liquids and the properties of its gels. Macromolecules 20, 414-417 (1987).

24 Terech, P. \& Weiss, R. G. Low molecular mass gelators of organic liquids and the properties of their gels. Chem. Rev. 97, 3133-3160 (1997).

25 Kunitake, T., Okahata, Y., Shimomura, M., Yasunami, S. \& Takarabe, K. Formation of stable bilayer assemblies in water from single-chain amphiphiles. Relationship between the amphiphile structure and the aggregate morphology. J. Am. Chem. Soc. 103, 5401-5413 (1981).

26 Kunitake, T., Ihara, H. \& Okahata, Y. Phase separation and reactivity changes of phenyl ester substrate and imidazole catalyst in the dialkylammonium bilayer membrane. J. Am. Chem. Soc. 105, 6070-6078 (1983).

27 Ihara, H, Takafuji, M \& Sakurai, T. in Encyclopedia of Nanoscience and Nanotechnology (ed. Nalwa H.S) 473-495 (American Scientific Publishers, Valencia, CA, USA, 2004).

28 van Esch, J. H. \& Feringa, B. L. New functional materials based on self-assembling organogels: from serendipity towards design. Angew. Chem. Int. Ed. 39, 2263-2266 (2000).

29 Gronwald, O., Snip, E. \& Shinkai, S. Gelators for organic liquids based on self-assembly: a new facet of supramolecular and combinatorial chemistry. Curr. Opin. Colloid Interface Sci. 7, 148-156 (2002).

30 Ihara, H., Sakurai, T., Yamada, T., Hashimoto, T., Takafuji, M., Sagawa, T. \& Hachisako, H. Chirality control of self-assembling organogels from a lipophilic L-glutamide derivative with metal chlorides. Langmuir 18, 7120-7123 (2002).

31 Ihara, H., Yamaguchi, M., Takafuji, M., Hachisako, H., Hirayama, C. \& Yamada, K. Production of helical bilayer membranes from L-glutamic acid derivatives with bis (dodecylamide) groups and their specific optical activity. J. Chem. Soc. Jpn., Chem. Ind. Chem. 10, 1047 (1990).

32 Takafuji, M., Kira, Y., Tsuji, H., Sawada, S., Hachisako, H. \& Ihara, H. Optically active polymer film tuned by a chirally self-assembled molecular organogel. Tetrahedron 63 , 7489-7494 (2007).

33 Takafuji, M., Ihara, H., Hirayama, C., Hachisako, H. \& Yamada, K. Functional organic gels - chirality induction through formation of highly-oriented structure. Liq. Cryst. 18, 97-99 (1995).

34 Jintoku, H., Kao, M.-T., Del Guerzo, A., Yoshigashima, Y., Masunaga, T., Takafuji, M. \& Ihara, H. Tunable Stokes shift and circularly polarized luminescence by supramolecular gel. J. Mater. Chem. C 3, 5970-5975 (2015).

35 Jintoku, H., Sagawa, T., Miyamoto, K., Takafuji, M. \& Ihara, H. Highly efficient and switchable electron-transfer system realised by peptide-assisted J-type assembly of porphyrin. Chem. Commun. 46, 7208-7210 (2010).

36 Jintoku, H., Sagawa, T., Takafuji, M. \& Ihara, H. Noncovalent one-to-one donor-acceptor assembled systems based on porphyrin molecular gels for unusually high electron-transfer efficiency. Chemistry 17, 11628-11636 (2011).

37 Jintoku, H. \& Ihara, H. Molecular gel-mediated UV-to-visible spectral conversion for enhancement of power-conversion efficiency. Chem. Commun. 48, 1144-1146 (2012).

38 Sagawa, T., Fukugawa, S., Yamada, T. \& Ihara, H. Self-assembled fibrillar networks through highly oriented aggregates of porphyrin and pyrene substituted by dialkyl L-glutamine in organic media. Langmuir 18, 7223-7228 (2002).

39 Takafuji, M., Ishiodori, A., Yamada, T., Sakurai, T. \& Ihara, H. Stabilization of enhanced chirality from pyrene-containing L-glutamide lipid in methyl methacrylate by photo-induced polymerization. Chem. Commun. 10, 1122-1123 (2004).

40 Hachisako, H., Ihara, H., Kamiya, T., Hirayama, C. \& Yamada, K. Thermal isomerization process in benzene gels of L-glutamic acid-derived lipids with spiropyran head groups. Chem. Commun. 19-20 (1997).

41 Hachisako, H., Nakayama, H. \& Ihara, H. Determination of critical aggregation concentrations of self-assembling lipids in nonpolar organic media using spiropyrans as photochromic probes. Chem. Lett. 28, 1165-1166 (1999).

42 Miyamoto, K., Sawada, T., Jintoku, H., Takafuji, M., Sagawa, T. \& Ihara, H. Controlled emission enhancement and quenching by self-assembly of low molecular weight thiophene derivatives. Tetrahedron Lett. 51, 4666-4669 (2010).

43 Watanabe, N., Jintoku, H., Sagawa, T., Takafuji, M., Sawada, T. \& Ihara, H. Selfassembling fullerene derivatives for energy transfer in molecular gel system. JPCS 159 (2009)

44 Ihara, H., Takafuji, M., Hirayama, C. \& O'Brien, D. F. Effect of photopolymerization on the morphology of helical supramolecular assemblies. Langmuir 8, 1548-1553 (1992).

45 Kira, Y., Okazaki, Y., Sawada, T., Takafuji, M. \& Ihara, H. Amphiphilic molecular gels from $\omega$-aminoalkylated L-glutamic acid derivatives with unique chiroptical properties. Amino Acids 39, 587-597 (2010). 
46 Okazaki, Y., Jintoku, H., Takafuji, M., Oda, R. \& Ihara, H. Creation of a polymer backbone in lipid bilayer membrane-based nanotubes for morphological and microenvironmental stabilization. RSC Adv. 4, 33194-33197 (2014).

47 Ihara, H., Hachisako, H., Hirayama, C. \& Yamada, K. Lipid membrane analogues. Formation of highly-oriented structures and their phase separation behaviour in benzene. J. Chem. Soc. Chem. Commun. 1244-1245 (1992).

48 Yamada, K., Ihara, H., Ide, T., Fukumoto, T. \& Hirayama, C. Formation of helical super structure from single-walled bilayers by amphiphiles with oligo-L-glutamic acidhead group. Chem. Lett. 13, 1713-1716 (1984).

49 Jintoku, H., Okazaki, Y., Ono, S., Takafuji, M. \& Ihara, H. Incorporation and template polymerization of styrene in single-walled bilayer membrane nanotubes. Chem. Lett. 40 561-563 (2011).

50 Jintoku, H., Sagawa, T., Sawada, T., Takafuji, M. \& Ihara, H. Versatile chiroptics of peptide-induced assemblies of metalloporphyrins. Org. Biomol. Chem. 8, 1344-1350 (2010).

51 Xue, P., Lu, R., Chen, G., Zhang, Y., Nomoto, H., Takafuji, M. \& Ihara, H. Functional organogel based on a salicylideneaniline derivative with enhanced fluorescence emission and photochromism. Chemistry 13, 8231-8239 (2007).

52 Xue, P., Xu, Q., Gong, P., Qian, C., Ren, A., Zhang, Y. \& Lu, R. Fibrous film of a two-component organogel as a sensor to detect and discriminate organic amines. Chem. Commun. 49, 5838-5840 (2013).

53 Xue, P., Sun, J., Yao, B., Gong, P., Zhang, Z., Qian, C., Zhang, Y. \& Lu, R. Strong emissive nanofibers of organogels for the detection of volatile acid vapors. Chemistry 21, 4712-4720 (2015).

54 Ihara, H., Yamada, T., Nishihara, M., Sakurai, T., Takafuji, M., Hachisako, H. \& Sagawa, T. Reversible gelation in cyclohexane of pyrene substituted by dialkyl L-glutamide: photophysics of the self-assembled fibrillar network. J. Mol. Liq. 111, 73-76 (2004).

55 Simonyi, M., Bikadi, Z., Zsila, F. \& Deli, J. Supramolecular exciton chirality of carotenoid aggregates. Chirality 15, 680-698 (2003).

56 Jintoku, H., Takafuji, M., Oda, R. \& Ihara, H. Enantioselective recognition by a highly ordered porphyrin-assembly on a chiral molecular gel. Chemical Communications 48 , 4881-4883 (2012).

57 Ihara, H., Takafuji, M. \& Kuwahara, Y. Japanese Patent Application No. 2015-239565 (2015).

58 Ihara, H., Okazaki, Y., Goto, T., Takafuji, M. \& Kuwahara, Y. Luminescent supramolecular gel-based transparent polymer film for light management. The 2015 EMN Hong Kong Meeting, Hongkong, China (2015).

59 Jintoku, H., Yamaguchi, M., Takafuji, M. \& Ihara, H. Molecular gelation-induced functional phase separation in polymer film for energy transfer spectral conversion. Adv. Funct. Mater. 24, 4105-4112 (2014).

60 Jintoku, H., Dateki, M., Takafuji, M. \& Ihara, H. Supramolecular gel-functionalized polymer films with tunable optical activity. J. Mater. Chem. C 3, 1480-1483 (2015).

61 Choy, W. C. H., Chan, W. K. \& Yuan, Y. Recent advances in transition metal complexes and light-management engineering in organic optoelectronic devices. Adv. Mater. 26, 5368-5399 (2014).

$62 \mathrm{Yu}$, E. T. \& van de Lagemaat, J. Photon management for photovoltaics. MRS Bull. 36 424-428 (2011)

63 Wang, F., Han, Y., Lim, C. S., Lu, Y., Wang, J., Xu, J., Chen, H., Zhang, C., Hong, M. \& Liu, X. Simultaneous phase and size control of upconversion nanocrystals through lanthanide doping. Nature 463, 1061-1065 (2010).

64 van de Rijke, F., Zijlmans, H., Li, S., Vail, T., Raap, A. K., Niedbala, R. S. \& Tanke, H.J. Up-converting phosphor reporters for nucleic acid microarrays. Nat. Biotech. 19 273-276 (2001)

65 Wang, F. \& Liu, X. Recent advances in the chemistry of lanthanide-doped upconversion nanocrystals. Chem. Soc. Rev. 38, 976-989 (2009).

66 Gnach, A. \& Bednarkiewicz, A. Lanthanide-doped up-converting nanoparticles: merits and challenges. Nano Today 7, 532-563 (2012).

67 Zheng, W., Tu, D., Huang, P., Zhou, S., Chen, Z. \& Chen, X. Time-resolved luminescent biosensing based on inorganic lanthanide-doped nanoprobes. Chem. Commun. 51 4129-4143 (2015).

68 Weifeng, Y., Xiyan, L., Dongzhi, C., Hongjie, Z. \& Xiaogang, L. Lanthanide-doped upconversion materials: emerging applications for photovoltaics and photocatalysis. Nanotechnology 25, 482001 (2014).

69 Yu, J., Yang, Y., Fan, R., Liu, D., Wei, L., Chen, S., Li, L., Yang, B. \& Cao, W. Enhanced near-infrared to visible upconversion nanoparticles of $\mathrm{Ho}^{3+}-\mathrm{Yb}^{3+}-\mathrm{F}^{-}$tri-doped $\mathrm{TiO}_{2}$ and its application in dye-sensitized solar cells with $37 \%$ improvement in power conversion efficiency. Inorg. Chem. 53, 8045-8053 (2014).

70 Kanosue, K., Shimosaka, T., Wakita, J. \& Ando, S. Polyimide and imide compound exhibiting bright red fluorescence with very large stokes shifts via excited-state intramolecular proton transfer. Macromolecules 48, 1777-1785 (2015).

71 Chu, Q., Medvetz, D. A. \& Pang, Y. A polymeric colorimetric sensor with excited-state intramolecular proton transfer for anionic species. Chem. Mater. 19, 6421-6429 (2007).

72 Park, S., Kim, S., Seo, J. \& Park, S. Y. Strongly fluorescent and thermally stable functional polybenzoxazole film: excited-state intramolecular proton transfer and chemically amplified photopatterning. Macromolecules 38, 4557-4559 (2005).

73 Iwamura, M., Kimura, Y., Miyamoto, R. \& Nozaki, K. Chiral sensing using an achiral europium(III) complex by induced circularly polarized luminescence. Inorg. Chem. 51, 4094-4098 (2012)

74 Prodi, L, Montalti, M \& Zaccheroni, N in Topics in Current Chemistry (eds. Prodi L., Montalti M. \& Zaccheroni N.) 175-216 (Springer, Berlin, Germany, 2011).

75 Wagenknecht, C., Li, C.-M., Reingruber, A., Bao, X.-H., Goebel, A., Chen, Y.-A., Zhang, Q., Chen, K. \& Pan, J.-W. Experimental demonstration of a heralded entanglement source. Nat. Photonics 4, 549-552 (2010).

76 Sato, I., Sugie, R., Matsueda, Y., Furumura, Y. \& Soai, K. Asymmetric synthesis utilizing circularly polarized light mediated by the photoequilibrium of chiral olefins in conjunction with asymmetric autocatalysis. Angew. Chem. 116, 4590-4592 (2004).

77 Peeters, E., Christiaans, M. P. T., Janssen, R.A.J., Schoo, H. F. M., Dekkers, H. P.J. M. \& Meijer, E.W. Circularly polarized electroluminescence from a polymer lightemitting diode. J. Am. Chem. Soc. 119, 9909-9910 (1997)

78 Kano, K., Matsumoto, H., Hashimoto, S., Sisido, M. \& Imanishi, Y. A chiral pyrene excimer in.gamma.-cyclodextrin cavity. J. Am. Chem. Soc. 107, 6117-6118 (1985).

79 Inouye, M., Hayashi, K., Yonenaga, Y., Itou, T., Fujimoto, K., Uchida, T.-a., Iwamura, M. \& Nozaki, K. A doubly alkynylpyrene-threaded [4]rotaxane that exhibits strong circularly polarized luminescence from the spatially restricted excimer. Angew. Chem. Int. Ed. 53, 14392-14396 (2014).

80 Meskers, S. C. J., Peeters, E., Langeveld-Voss, B. M. W. \& Janssen, R. A. J. Circular polarization of the fluorescence from films of poly( $p$-phenylene vinylene) and polythiophene with chiral side chains. Adv. Mater. 12, 589-594 (2000).

81 Leonard, J. P., Jensen, P., McCabe, T., O'Brien, J. E., Peacock, R. D., Kruger, P.E. \& Gunnlaugsson, T. Self-assembly of chiral luminescent lanthanide coordination bundles. J. Am. Chem. Soc. 129, 10986-10987 (2007).

82 Imai, Y., Murata, K., Nakano, Y., Harada, T., Sato, T., Tajima, N., Fujiki, M., Kuroda, R. \& Matsubara, Y. Solid-state optical properties of a chiral supramolecular organic fluorophore consisting of fluorescent 1-pyrenesulfonic acid and amine molecules. Eur. J. Org. Chem. 2009, 3244-3248 (2009).

83 Kinuta, T., Kamon, K., Harada, T., Nakano, Y., Tajima, N., Sato, T., Fujiki, M., Kuroda, R., Matsubara, Y. \& Imai, Y. Solid-state chiral supramolecular organic fluorophore having a $\pi$-conjugated phenylene ethynylene unit. Eur. J. Org. Chem 2009, 5760-5764 (2009)

84 Carr, R., Evans, N. H. \& Parker, D. Lanthanide complexes as chiral probes exploiting circularly polarized luminescence. Chem. Soc. Rev. 41, 7673-7686 (2012).

85 Shen, Z., Wang, T., Shi, L., Tang, Z. \& Liu, M. Strong circularly polarized luminescence from the supramolecular gels of an achiral gelator: tunable intensity and handedness. Chem. Sci. 6, 4267-4272 (2015).

86 Ihara, H. Supramolecular gel-based luminescent film for light management. The Ceramic Society of Japan, The 28th Fall Meeting, Toyama, Japan (2015).

87 Hatano, T., Bae, A. H., Takeuchi, M., Fujita, N., Kaneko, K., Ihara, H., Takafuji, M. \& Shinkai, S. Helical superstructure of conductive polymers as created by electrochemical polymerization by using synthetic lipid assemblies as a template. Angew. Chem. Int. Ed. 43, 465-469 (2004)

88 Xue, P., Lu, R., Yang, X., Zhao, L., Xu, D., Liu, Y., Zhang, H., Nomoto, H., Takafuji, M. \& Ihara, H. Self-assembly of a chiral lipid gelator controlled by solvent and speed of gelation. Chemistry 15, 9824-9835 (2009).

89 Gopal, V., Xavier, J., Kamal, M. Z., Govindarajan, S., Takafuji, M., Soga, S., Ueno, T., Ihara, H. \& Rao, N. M. Synthesis and transfection efficiency of cationic oligopeptide lipids: role of linker. Bioconjugate Chem. 22, 2244-2254 (2011).

90 Wang, X., Duan, P. \& Liu, M. Universal chiral twist via metal ion induction in the organogel of terephthalic acid substituted amphiphilic I-glutamide. Chem. Commun. 48, 7501-7503 (2012)

91 Miao, W., Zhang, L., Wang, X., Cao, H., Jin, Q. \& Liu, M. A dual-functional metallogel of amphiphilic copper(II) quinolinol: redox responsiveness and enantioselectivity. Chem istry 19, 3029-3036 (2013).

92 Ogawa, T., Yanai, N., Monguzzi, A. \& Kimizuka, N. Highly efficient photon upconversion in self-assembled light-harvesting molecular systems. Sci. Rep. 5, 10882 (2015)

93 Duan, P., Yanai, N., Nagatomi, H. \& Kimizuka, N. Photon upconversion in supramolecular gel matrixes: spontaneous accumulation of light-harvesting donoracceptor arrays in nanofibers and acquired air stability. J. Am. Chem. Soc. 137, 1887-1894 (2015). 